\title{
'Working Backwards Makes you Think!' Constructing and Presenting Case Studies to Understand Methodology and Theory in a Communication Masters Course
}

\author{
Jane Hiscock* \\ University of South Australia, School of Communication, Adelaide, South Australia 5001, Australia
}

\begin{abstract}
This paper analyses student construction of case studies, using dialogue and role plays, to stimulate and consolidate understand of organization communication research, theory and methodology. Students undertaking a course as part of a Masters program in communication management need to absorb a range of organizational research perspectives and organizational communication theories. Making the theorists and methodological perspectives 'about you' is one way of stimulating interest and engagement with demanding and complex concepts. Student response to the case study construction and some dialogue examples are included.
\end{abstract}

Keywords: Experiential learning, case studies, communication theories.

\section{INTRODUCTION}

The course 'Researching communication in the organizational context' is a prerequisite for a final course in the Masters program where students design and undertake their own research project. Both qualitative and quantitative research approaches and their combinations are acknowledged. This paper focuses on the qualitative elements.

The students come from a variety of backgrounds and countries. Most are working full-time and studying parttime. They work in a range of communication roles in government, business, industry and the private sector. They often have little or no research experience and are unfamiliar with the methodology and theory surrounding organizational communication research.

The double -sized course is taught intensively face-toface, using a variety of methods, including use of cinema clips and textbook case studies. The course is assessed via a proposal, a literature review and a piece of major analysis (proposed but without actual data collection) all based around an organizational communication issue selected by the students from their own experience and often their own workplace.

The aim of this paper is to analyse the teaching of theory and methodology via case study construction and presentation and to evaluate its relevance in the sphere of experiential learning.

A qualitative approach to the analysis of feedback to the course is provided through student case study dialogue and responses to the course.

\section{EXPERIENTIAL LEARNING}

The University, in common with other universities, has a current teaching emphasis on experiential learning. Boud (1989) talked about the concept of experiential learning in'

Address correspondence to this author at the University of South Australia, School of Communication, Adelaide, South Australia 5001, Australia; Tel: 088302 4533; Fax: 088302 4745;

E-mail: jane.hiscock@unisa.edu.au volving learner control, the learner's involvement of self and links between the learning environment and the real environment. Boud (1989) also called the experiential learning approach (Illeris, 2007, p. 86) 'individual centred', 'groupcentred 'and project-centred.

Illeris (2007, p. 94) emphasises the importance of the connection between learner and content, saying "What kind of prior learning has the learner been through in relation to the learning area in question/ What kind or interest and motivation is involved? ... What kind of activity is likely to make the learner engage himself or herself in the topic or ability the learning is about?' These questions form the approach to the analysis of the teaching in the course.

Keating (2006, p. ii) emphasises the relevance of the workplace for learning, saying;

The workplace is increasingly being seen as a legitimate site for learning within formal educational programs. There are a number of drivers for this approach including the changing nature of work and developing ideas about how knowledge is produced and used outside universities'. He adds; Workplace learning is a form of experiential learning. Powerful learning can occur in the workplace. place.

Reflection is an essential part of learning in the work-

Learning in the workplace cannot be separated from participation in work.

As has been stated, students are encouraged to view their workplace as a site for research as students and workers.

The University, in common with other universities, has a set of graduate qualities (University of South Australia, 2008) where a graduate of the University;

Operates effectively with and upon a body of knowledge of sufficient depth to begin professional practice.

Is prepared for life-long learning in pursuit of personal development and excellence in professional practice. 


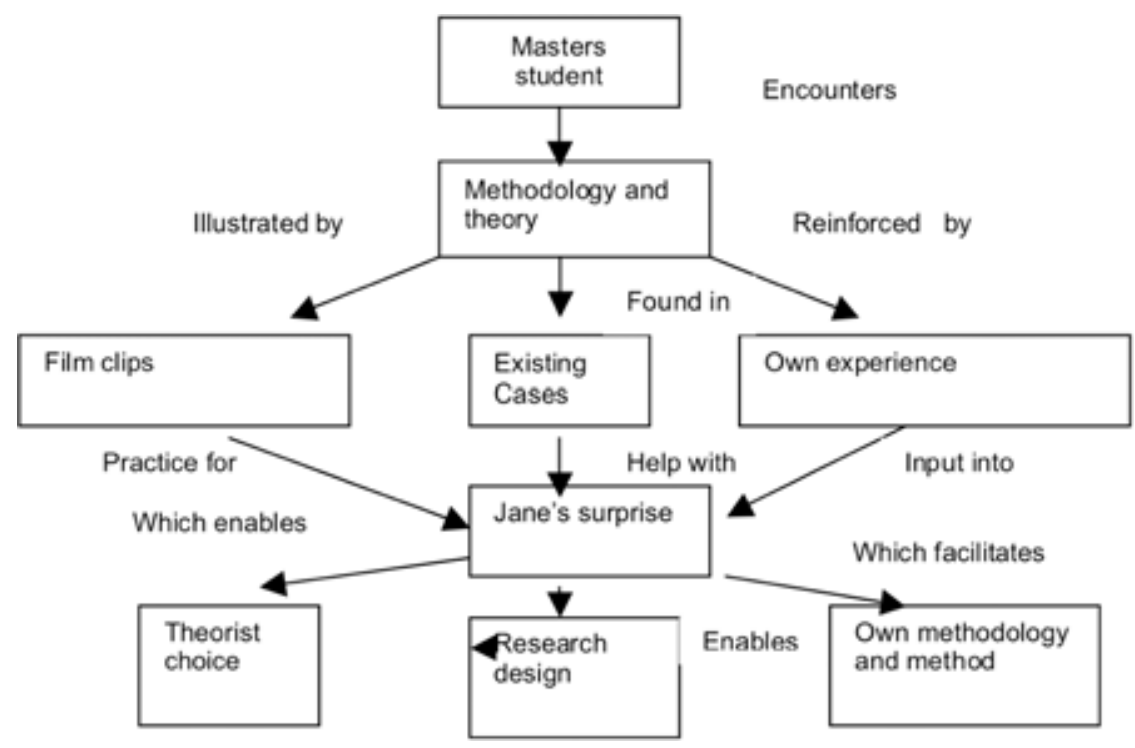

Fig. (1). Concept map showing the connections between the teaching methods of the course.

Is an effective problem solver, capable of applying logical, critical, and creative thinking to a range of problems.

Can work both autonomously and collaboratively as a professional.

Is committed to ethical action and social responsibility as a professional and citizen.

Communicates effectively in professional practice and as a member of the community.

Demonstrates international perspectives as a professional and as a citizen.

These qualities are embodied in the course and the case study construction. Students first encounter the methodological perspectives and theory through written texts and then combine these with selected film clips, existing case studies and their own experience which they exchange in small groups.

A discussion on methodology and theory will be illustrated by examples from the course. The teaching methods used all link to one another and culminate in the case study construction task, which is the final teaching activity in the intensive course (taught in evening and Saturday face-to-face blocks).

The use of case studies and film clips in teaching are well documented. This paper discusses an unusual combination of these two methods where students watch film clips illustrating core concepts and assist each other by writing/presenting their own case studies and devising questions for other students to answer.

The concept map below (Fig. 1) shows the teaching methods used in the course.

\section{METHODOLOGICAL PERSPECTIVES}

For this course three main methodological approaches to organisational communication research were introduced and discussed. These are broadly - Classical/traditional, Interpretive, and Critical.
The classical perspective is the oldest and has evolved from viewing the organization as a machine to viewing the organization as a living system. For this course it includes theorists such as Taylor (1947), Fayol (1949), and Weber (1969) and more recently, Jacques (1990).

The interpretive perspective views organizations as cultures and organizational reality as socially constructed through our interaction with one another. Theorists represented here include Geertz (1973) Smircich (1983) and Schein (1985).

By contrast, the critical approach views organizations as sites of power and oppression. Theorists here include Kanter (1979), Mintzberg (1983), Pepper (1995) and Miller (2006). Taylor and Trujillo (2001, p. 170) acknowledge the 'productive tensions' between the interpretive and critical approach to qualitative analysis saying the 'critical challenge ......is a 'reminder that power is a prevalent and naturalized phenomena that we should consider in organizational research.. and 'critical theorists have challenged us to actually emancipate those who are oppressed by organizations'.

The major theorists are discussed within these broad perspectives. It is made clear to students that a combination of perspectives is likely when undertaking research and that the theorists and perspectives are not mutually exclusive of one another.

\section{Film Clips}

Cinema has been used in a wide range of disciplines and educational levels, including management (Dunphy, 2007) and nursing (Masters, (2005). Bali and Wickramasinghe (2007) conducted a longitudinal research study into the use of film to demonstrate academic concepts. They cited the use of film as case study, experiential learning, metaphor, meaning, experience and behaviour, using students of management. They suggest $(2007$, p. 149) ' For students who enter into the workforce they are better prepared to manage critical scenarios which they have never experienced before by ap- 
plying concepts they have come to understand not just as theories in a book but concepts in action.'

For the students in this paper, the film clips were intended as a preparation for construction of the case study which is the culmination of the course. The cinema clips were useful for both theorists and methodological perspectives. Short excerpts (approximately 5 mins) of free to air films which had previously been screened on free to air television were used in the classroom, interspersed with mini lectures, seminars and group work made possible by the intensive teaching sessions. Some examples are discussed here. Film clips are intended to illustrate theorists and to encourage the students to begin to think like a researcher, when they come to design their own research projects. Where possible humorous film clips are selected to add to the impact.

For the classical organisational perspective in the film 'Jabberwocky' (1977) from the UK - Dennis (Michael Palin) the Apprentice's visit to the armory and his disastrous suggestions about efficiency are an exaggeration of the classical principles of organization theory. Students were asked to look for signs of a classical organizational structure and operation.

For the interpretive perspective film clips were chosen to illustrate a range of organizational cultures. Schein's 1985 model of culture suggests three levels of culture artifacts, the most visible level, espoused values as Miller (2006, p. 109) says 'a mosaic of beliefs about how things ought to be done in an organization' and basic assumptions which are (Miller 2006, p. 110) 'core assumptions that individuals in a group hold about the world and how it works'. Students were asked to apply Schein' s definition of culture to three film extractsto be researchers and to look for clues to the organizational culture depicted. This, of course, includes attention to dialogue, which also assists with constructing their own dialogue in the case study exercise and looking at the real life levels of culture all around them.

One film was 'Spotswood' (1992) an Australian film about a management consultant (Anthony Hopkins) visiting a moccasin factory to work out efficiencies. Another was 'In good company' (2004) - an American film where a young executive (Topher Grace) becomes head of sports advertising company, taking over the role from an older man with 20 years of professional experience.

The well-known film about the collapse of Enron, 'Enron, the smartest guy in the room' (2005) provided a reallife example of aspects of organizational culture, such as symbolic convergence theory and prompted a discussion of ethics. Borman's (1982) symbolic convergence theory refers to as Pepper (1995, p. 19) states 'the rhetorical construction of reality through the accomplishment of shared meaning among group members. In other words, as group members transact with each other, their understandings of the group experience - the reality of the event- is shaped by their language'.

To illustrate ethics an exaggerated display of unethical behavior and dialogue was illustrated by a short excerpt from the film 'Intolerable cruelty' (2003), in the initial exchange between the matrimonial lawyer Miles Massey and his ethics free client, Rex Rethroth.
To show power play in an organization, a clip from 'Clear and present danger' (1994) where two top CIA staff, Cutter and Ritter negotiate a power relationship (Harrison Ford is absent from this scene) aptly illustrates the theorists about power in organizations. Power theorists include Pepper (1995) whose work on power, politics and conflict negotiation is echoed by other theorists. Students view the scene from an interpretive and a critical perspective and apply the relevant theorist in their analysis. They can also focus on the language/discourse of the dialogue and apply the perspectives of Derrida (1976) and Foucault (1979) to the film clips. Foucault suggested that (Papa, Daniels, Spiker 2008 p. 310) 'more than one discursive formation may be present in a single organization', and the students are aware of this.

Students gained practice in observing, interpreting and analyzing situations according to a range of theoretical and methodological perspectives. They did this in different group combinations and also by themselves. Their differing affinity for theorists and methodologies meant that a range of interpretations were represented. Their life experience also played a large role in their application of course theorists to selected scenarios.

\section{CONSTRUCTING A CASE STUDY}

The use of case studies such as those in Hunt (1985) Miller (2006) and Taylor and Pettit (2007) is also widespread as a way of involving students in their own learning. Typically this involves small group work where students read a case study from a textbook and respond to questions which illustrate a particular point. Boggs, Mickel and Holtom (2007) discuss experiential learning through interactive drama as an alternative to role-plays, where trained actors perform for students.

What is different for this course in this paper is that the students construct their own case studies, write and present the dialogue for the case study and construct some questions at the end of the study for other groups to answer. This is a complex task. Students learn to apply theory and methodological perspectives, collaborate of writing dialogue, present a scenario and give feedback to one another on the responses to the questions they have constructed for their peers. This is 'experiential learning' with a focus on student control of the learning environment. As the students are taking an intensive course there is an opportunity for some concentrated group work and groups of 4-5 students work well. This is the final task of the intensive course, so students are used to working together by this time.

Another important aspect is for the group to reflect on the group dynamic, the decision making and the power plays, theorists for which form part of the methodological perspectives and theorists studied in the course. These theorists are applied both to the film clips and the case studies and to the student group dynamics which they observe as they interact with one another for the course task.

The case study exercise is listed as 'Jane's surprise', at the end of the final session, prompting the question from the students 'What is the surprise?' To which the only response is. 'If I tell you, it is not a surprise'. 
Here is (Fig. 2) what the students receive:

This exercise will utilise your skills, experience and knowledge of theorists and perspectives covered in this course. It will also give you insights into how you might approach the assignments for RCOC. You will be engaging with group dynamics and using your communication skills-also an emphasis of the course.

1. Construction stage

Working in your groups, construct an organizational communication event, using theorists from today

Write a background to this event and then construct 5 minutes max of dialogue, giving a role to each person in your group and illustrating your communication event. Give the event a name.

Write the background and the dialogue into a word file and email it to the course coordinator for distribution to the class.

Decide on 3 questions which are relevant to your case study and add them to the bottom of your file. These questions will be answered by the other group when they have seen your dialogue/presentation.

Practice your dialogue with various people reading their parts.

2. Presentation stage

Present your case study to the other group. You will all have copies of all of the dialogue presented.

Include reflections on the group dynamic as you undertook this exercise - you might like to ask one person in the group to take a few notes on the process.

3. Synthesis

Spend time in your group answering the questions devised by the other group from their case study. You might decide to all do all of the questions or some might focus on one question only to make a response.

Hear one another's responses to the questions you have constructed as part of your group designed case study. Responses to be presented on the OHP slides as we have done for the other case studies in the course.

Say what you were attempting to illustrate and what you think the strength of your presentation is. Consolidate your understanding of the some of the theorists presented in the course.

4. Congratulate yourselves on a job well done!

Fig. (2). Case study construction.

\section{RESULTS}

Two examples of Jane's surprise indicate that students warm to the task, which requires that a part be written for everyone in the group to read/perform. This brings out the writers/performers in the group - some of whom use props, but this is not expected. They are required to put themselves in a scenario which might be like one they could research and to use their understanding of the course materials to create the raw material of the case study. In some cases international students are given culturally specific roles, such as a Hong Kong golfing buddy in one scenario.

The scenarios are lively and interesting with plenty of insight into power roles and organizational communication strategies. Titles are also enthusiastically addressed, such as 'Sideways- the stage show' and 'She holds his tee' a play on words representing a personal assistant juggling conflict between work and a regular golf game.

Two examples (Figs. 3 and 4) of dialogue are included below.

Responses to the questions from other groups involved discussion of several methodological perspectives and a range of interpretations of styles of conflict and theorists who define power. Mumby (1987, p. 115) talks about the deep structure of an organization, where ' domination involves getting people to organize their behavior around a particular rule system'. As Papa, Daniels and Spiker, talking about the critical approach to organizational communication (2008, p. 12) state 'Organizational oppression does not reside in structure alone or in symbols alone. It resides in the relationship between structure and symbols.'

The five conflict styles refers to Thomas (1988) map of five conflict styles, incorporating competitive, collaborative, avoidance, accommodation and compromise, along two axes. Students were able to apply this model to their own experience and acknowledged that in real life styles are adapted to circumstances and vary widely.

Other input into the discussion focussed on the language used. The theorist Louis (1980) provided insight into the sense making efforts of the new recruit and there was some general awareness of the organizational culture of the organization offered by Schein (1985).

This scenario used humor (such as naming the nonspeaking character after the course coordinator) and introduced elements of ethics and gender into the theoretical and methodological mix.

The group also reported on their group decision making process - citing Janis (1972) 'groupthink' phenomenon where, according to (Papa, Daniels and Spiker, 2008, p. 325) 'individual members surrender their own beliefs and begin to see things only from the group perspective' to complete the task. The complex interplay of power and communication was enthusiastically performed. Students answering the questions used the techniques they had practised with the film clips to observe the cues about the culture of the organization and to recognize the theorists emphasized in the course.

\section{Student Responses to the Task}

After the course students responded to open text questions about aspects of the teaching via an anonymous survey link which they could access electronically.

In class students congratulated one another on responses to the questions they devised for one another. They were aware that they would have to respond to some other case study and report back to the whole class with a group presen- 




Fig. (3). Example 1 of case study construction.

tation response. They asked themselves, as one student said 'Shall we make the questions hard or should we be nice?' and usually opted for a mixture. There is an element of competition between groups and an eagerness to show one another their level of understanding.

They acknowledged the complexity of the task and said it was 'Challenging' 'Hard work... 'Good fun' and said ' students cannot write anything if they do not understand the context of the course, It helps us to think about the real situation and refer to the theories'.

Other comments echoed these, it reinforced the key points as we had to actively consider the theories when writing the script' and 'It helped to clarify the various perspectives used and how theory can be applied to understand the dynamics of what is going on.' Another comment 'Working backwards makes you think! showed that the students understood the purpose of the exercise.

When asked about constructing dialogue students also said it was a useful exercise. Comments such as 'I go deep into each case study', 'it's very practical' 'you also had to think about what the characters were saying and why' and 'doing the dialogue helped me understand the theorists' and 'applying theorists' perspectives to our 'own', albeit made up situation, brought them down to the 'everyday' level and therefore made us see how the theorists apply to our daily lives'.

All students in their written work showed a facility with methodological perspectives and understanding of theorists and recognized the link between their own group work and this understanding.

One student said 'keep Jane's surprise' for future years as they found it had brought theory and methodology and therefore research alive.

\section{DISCUSSION}

The student responses indicate the development of a range of skills which are used and recognized to undertake the construction of the case study. The use of film clips and textbook case studies also provide input into their own work. Writing introduces another level of involvement in experiential learning.

Writing dialogue as a group is a complex task requiring a high level of effort and giving everyone a dialogue role also ensures the involvement of every individual. Linking the construction to theorists and methodology already covered means that students go over course materials and consolidate their knowledge. Deciding what sort of questions to ask to showcase the knowledge and intentions of the group demands their full attention as they will be assessing the responses of other groups to their efforts and want to be clear about what their case study is illustrating, as well as stimulating some worthwhile discussion.

The questions Illeris (2007) asks in the early part of this paper, when applied to the case study construction, indicate a strong degree of student involvement and incorporation of prior learning in the form of their own experience in the workplace. 'Working backwards' by making up their own 


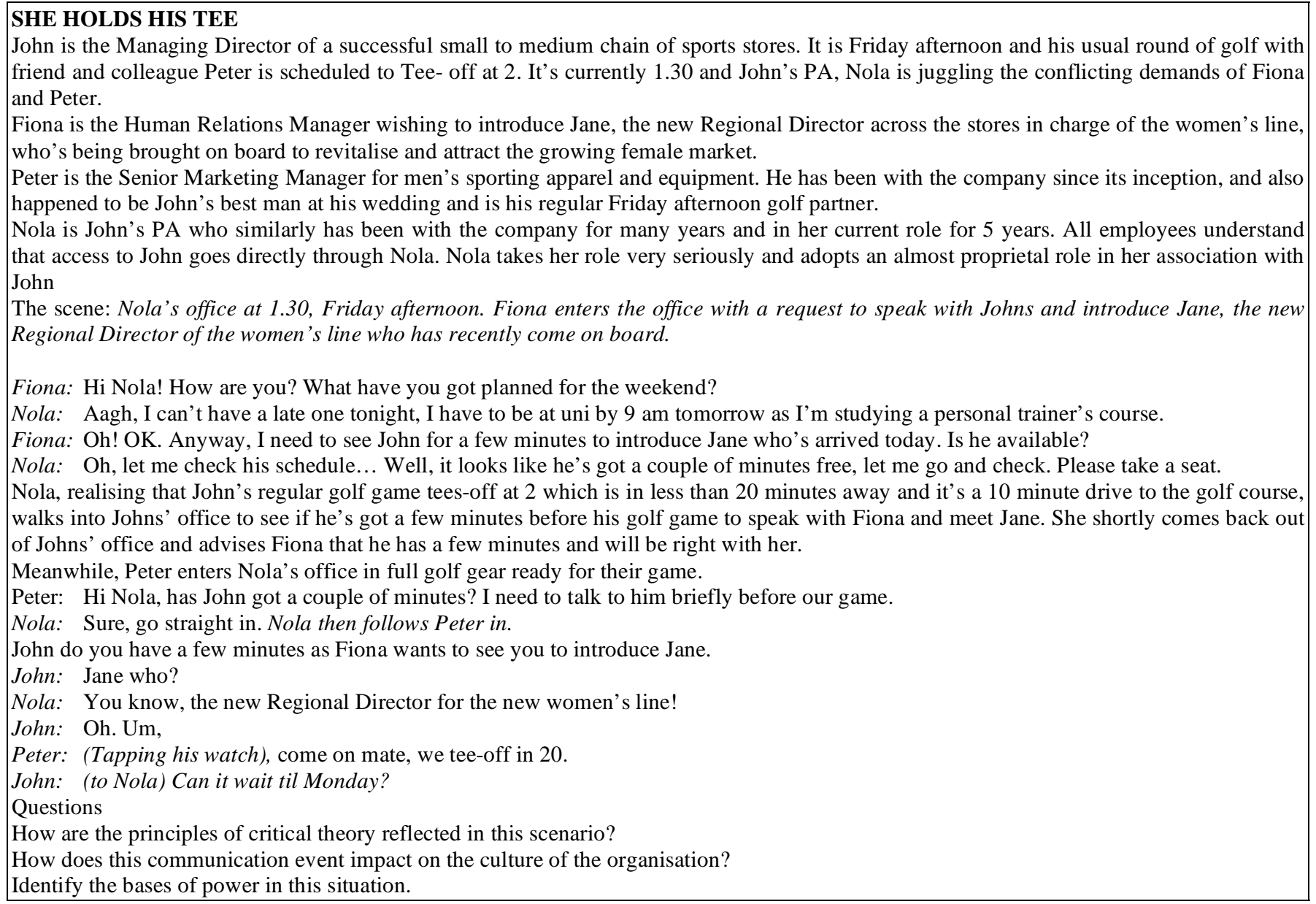

Fig. (4). Example 2 of case study construction.

case studies after viewing film clips and reading existing case studies does give students a strong understanding of how all the theorists and methodological perspectives of the course fit together and how they can use them in their own research.

This task incorporates the graduate qualities of problem solving skills, effective communication, body of knowledge, ethical action, working autonomously and collaboratively, and lifelong learning. It can readily be seen that theory and methodology is in fact 'about you' and is strongly linked with personal experience and both professional and personal life.

\section{TEACHING REQUIREMENTS}

Using well-known films and trying to use film clips which incorporate humour makes the exercise memorable. Where students had seen the film and knew the story a discussion of what happens served to consolidate the purpose of the inclusion of the film clip.

Students know each other from previous courses and are used to working in various group combinations in this course, which is near the end of the Masters program. This task would be harder to organise without this existing familiarity. Students also need separate spaces to construct and prepare/practice their dialogue without interference from other groups, and access to a computer to create the case study as they go.

It is also important for the course coordinator to balance the groups by deciding who goes where and trying to balance gender, English language skills, assertiveness and any other characteristic which is best spread over the range of available groups.

The findings of Bali and Wickramasinghe (2007) are reinforced from student enthusiasm for the use of film clips to observe a complex situation and hear dialogue and think about communication and meaning in the interactions depicted. If the film chosen is familiar this also adds to their learning as the familiar is linked to the newly acquired knowledge.

\section{CONCLUSION}

The responses of the students indicate that methodology and theory come alive when 'working backwards' and watching other groups respond to the questions developed as part of the case study construction. The task actively prepares students to undertake their own research and utilizes their skills and experience and their powers of listening and observation, stimulated by the selected film scripts. These are fundamental research methods for a qualitative approach to organizational communication research. 
It is intended over time to use the case studies for future students and to develop the task as a possible assessment task and allow more out of class time for its construction.

\section{REFERENCES}

Bali, R. K. \& Wickramasinghe, N. (2007). Using film to demonstrate academic concepts. International Journal of Management in Education, $1, \operatorname{nos} 1 / 2,139-151$.

Boggs, J. G., Mickel, A. E. \& Holtom, B. C. (2007). Experiential learning through interactive drama: an alternative to student role plays. Journal of Management Education, 31, 6, 832-858.

Boud, D. (1989). Some competing traditions in experiential learning . In 'Making sense of experiential learning: diversity in theory and practice,' S .W. Weil \& I. McGill (Eds.) pp. 39-49 Buckingham UK, Open University Press.

Clear and present danger (1994). (videorecording) Paramount.

Derrida, J. (1976). Of grammatology (G Spivak trans) Baltimore, Johns Hopkins (original work published 1967).

Dunphy, S. (2007). using Hollywood's greatest film scenes to illustrate concepts of organisational behaviour and management. Behaviour and Information Technology, 26, 2 179-185.

Enron; the smartest guys in the room (2006). Magna Pacific.

Fayol, H. (1949). General and industrial management (Constance Storrs Trans) London, Sir Isaac Pitman.

Foucault, M. (1979). Discipline and punish: the birth of the prison. (A.S. Smith trans) NY, Random House (original work published 1975.

Geertz, C. (1973). The interpretations of cultures. NY, Basic Books.

Hunt, T. (1985). Instructional simulation helps public relations students to understand roles in organizational communication. Paper presented at the Annual Meeting of the Association for Education in Journalism and Mass Communication, 68th Memphis, TN, August 3-6.

Illeris, K. (2007). What do we actually mean by experiential learning? Human Resources Development Review, 6 no. 1, 84-95.

In good company (2005). (videorecording) Universal Studios.

Intolerable cruelty (2004). (videorecording) Universal Studios.

Jabberwocky (2001). (videorecording) Sony.

Jacques, E. (1990). In praise of hierarchy. Harvard Business Review, (January- February), 127-133.

Kanter, R. M. (1979). Power failure in management circuits. Harvard Business Review, (July-August), 65-75.
Keating, S. (2006). Learning in the workplace; a literature review. Victoria University. Retrieved March 12, 2008 from the World Wide Web

http://tls.vu.edu.au/PEC/PEC_docs/PEC\%20LIW\%20literature\%20review\% 20final.pdf

Louis, M. R. (1980). Surprise and sense making: what newcomers experience in entering unfamiliar organisational settings. Administrative Science Quarterly, 25, 2 (June), 226-251.

Masters, J. C. (2005). Hollywood in the classroom ; using feature films to teach. Nurse Educator, 30, 3, 113-116.

Miller, K. (2006). Organizational communication ; approaches and processes $4^{\text {th }}$ ed. South Bank, Thomson.

Mintzberg, H. (1983). The power game and the players. In 'Power in and around organizations'. New Jersey, Prentice Hall, p, 22-30.

Mumby, D.K. (1987). The political function of narrative in organizations. Communication Monographs, 54, 113-127.

Papa, M. J., Daniels, T., \& Spiker, B. K. (2008). Organizational communication : perspectives and trends. Los Angeles, Sage.

Pepper, Gerald L. (1995). Communicating in organizations: a cultural approach. New York, McGraw Hill.

Schein, E. H. (1985). Defining organizational culture. In 'Organizational culture and leadership'. San Francisco, Jossey Bass.

Smircich, L. (1981). The concept of culture and organizational analysis . paper presented at the SCA/ICA Conference on Interpretive Approaches to Organizational Communication Alta, UT.

Spotswood (1991). (videorecording) Meridien Films.

Taylor, B. B. \& Trujillo, N. (2001). Qualitative research methods. In 'The new handbook of organizational communication: advances in theory, research and methods.' F, M Jablin \& L L Putnam Eds . London, Sage.

Taylor, F. W. (1947). Principles of scientific management, New York, Harper \& Brothers.

Taylor, P. \& Pettit, J. (2007). Learning and teaching participation through action research, Action Research, 5,3, 231-247.

Thomas, K. W. (1988). The conflict-handling modes; towards a more precise theory. Management Communication Quarterly, 1, 30, 430436.

University of South Australia (2008). Graduate Qualities. Adelaide, University of South Australia.

Retrieved March 12, 2008 from the World Wide Web.

http://www.unisanet.unisa.edu.au/gradquals/default.asp

Weber, M. (1969). The theory of social and economic organizations. A.M. Henderson \& T. Parsons Trans T. Parsons Ed), New York, OUP. 